\title{
Descentralização os discursos e as práticas: uma concepção polissêmica*
}

\section{Decentralization discourses and practices: a polysemic concept}

Maria Rosa Dória Ribeiro*

\begin{abstract}
Resumo: Este ensaio teórico se desenvolve a partir do conceito de descentralização e de seu significado para a reconstrução das relações democráticas de poder. Analisa as interpretações e os usos do termo na perspectiva histórica das propostas de rearranjos estruturais do Estado como resposta à crise fiscal. Mas, também, como resposta às expectativas dos diferentes atores sociais quanto à importância da descentralização para o aprofundamento da Democracia no país.
\end{abstract}

Palavras-chave: Descentralização. Relações democráticas. Poder. Desconcentração.

Abstract: This theoretical essay is developed from the concept of decentralization and its significance for the reconstruction of democratic power relationships. It analyzes interpretations and uses of the term in the historical perspective of the proposed structural rearrangements of the State in response to the current fiscal crisis. It also offers a response to the expectations of different social actors about the importance of decentralization for deepening democracy in the country.

Keywords: Decentralization. Democratic relations. Power. Devolution.

Este ensaio teórico é fruto da reflexão sobre o papel da descentralização na reconstrução do Estado democrático brasileiro no período que se seguiu à queda da ditadura militar. Questionamentos sobre a história recente do país acerca das dinâmicas das relações políticas possibilitaram observar que a democracia aparece, historicamente, associada a processos de descentralização. No entanto, cabe indagar: a descentralização é portadora de quais significados na construção da democracia?

A descentralização do poder público está presente na história da organização do Estado brasileiro, mas particularmente nas últimas décadas ganhou visibilidade como projeto político tanto dos grupos que dirigem o país, como dos grupos que fazem oposição política aos detentores do poder. A descentralização está associada ao debate sobre as políticas sociais e, principalmente, sobre a chamada reforma do Estado. Na década de noventa do século $\mathrm{XX}$, o forte movimento de descentralização pôde ser visto, de uma parte, como resultante da crise fiscal do Estado; de outra, como reação ao autoritarismo presente na sociedade brasileira.

Descentralizar: afastar ou separar do centro; dar autonomia administrativa; aplicar o descentralismo, isto é, adotar o regime político em que os órgãos administrativos têm autonomia acentuada, e esses órgãos

* Doutora em História pela USP. E-mail: <miarosaster@gmail.com>.

Olhar de professor, Ponta Grossa, 14(2): 381-388, 2011. 
ficam tanto quanto possível desprendidos do poder central. Assim define o Dicionário Aurélio. Porém, ao se tratar de poder, a definição não parece tão simples, pois quanto mais se percorre a literatura sobre o tema, mais se encontram adjetivações agregadas ao núcleo da ideia que o altera ou lhe confere sutis - e não tão sutis - diferenças. Isso faz com que exista uma dispersão de conotações que confunde a todos e nos faz perder a substância da matéria. Alguns autores separam a descentralização política da administrativa, caracterizando a segunda como sendo a delegação, por uma organização pública, de algumas de suas funções ou tarefas a níveis subordinados, com a seguinte argumentação:

A redução de tamanho da burocracia, através da descentralização, presumivelmente levaria à melhor prestação de serviços, permitindo aos órgãos implementadores concentrá-los em áreas menores, reduzindo o volume de demandas no âmbito central. Desse modo, eles poderiam atender de perto a seus clientes, com maior agilidade, tornando seus programas mais bem administrados e ampliando seu impacto positivo. (MEDINA, 1987, p. 46)

A descentralização política, sob essa ótica, pressuporia uma mudança maior na forma de exercer o poder, uma vez que a autoridade passaria às mãos de "organizações ou residentes locais, com poderes gerais para decidir", que "tenderiam a aplicar seus recursos na busca de prioridades e interesses da localidade” (MEDINA, 1987, p.46).

Felicíssimo (1991), ao contrário, não acredita ser possível dissociar o caráter administrativo do caráter político no processo de descentralização, e desenvolve suas reflexões quanto ao rumo da descentralização considerando que ela pode partir de uma administração do público, para uma administração para o público, ou administração pelo público. Essa variação de rumo pode se dar de acordo com as disposições do poder que implementa o processo, de aprofundar mais, ou menos, a democratização das relações, sobretudo no caso do estabelecimento das políticas públicas.

Há outras visões, entretanto, que atribuem significados variados à descentralização, tais como: a) redistribuição do poder político intra e externamente ao Estado, para que a gestão das políticas públicas ocorra no contexto de uma democracia política e social: assim "gestão pública" não se resume a "gestão estatal"; b) processo que, essencialmente, objetivaria aumentar a autonomia de decisão e de controle dos recursos, as responsabilidades e as competências das coletividades, em detrimento dos órgãos do Estado central (PRETECEILLE, 1987); c) um meio para promover a socialização política das classes populares e o desenvolvimento das liberdades individuais, além de promover as transformações socioeconômicas de tendência igualitária, o que implicaria maior controle popular dos núcleos centrais de decisão, multiplicaria os poderes políticos locais, aumentaria o equilíbrio de decisão e o equilíbrio de poderes entre territórios, grupos sociais e indivíduos (BORJA, 1987); d) redistribuição do poder político na sociedade e um novo contrato social entre o Estado e a sociedade, no qual a descentralização político-territorial e o desenvolvimento regional transformar-se-iam em um só processo de construção social de uma região ou localidade que se converteria em sujeito de seu próprio desenvolvimento, sob o signo do consenso político entre os atores (BOISIER, 1987).

É possível concluir que, de uma maneira ou de outra, descentralizar implica uma alteração profunda na forma de exercer o poder político. Descentralizar significa o 
remanejamento do poder central, que passa a conferir autonomia política, financeira e administrativa às outras instâncias de poder público, envolvendo "necessariamente alterações nos núcleos de poder, que levam a uma maior distribuição do poder decisório até então centralizado em poucas mãos" (LOBO, 1990, p. 6). A descentralização pode também ser definida como "o ato de confiar o poder de decisão a órgãos diferentes dos do poder central, que não estejam submetidos ao dever de obediência hierárquica e - acrescentam alguns - que contem com autoridades eleitas democraticamente" (CASASSUS, 1995, p.66). Ou ainda, como analisa Felicíssimo, a partir dos estudos de Motta, "consiste em dar às coletividades o poder de gerir de forma autônoma seus próprios assuntos”. Mas, segundo esse autor, para que assim aconteça é necessário que as autoridades sejam eleitas pela coletividade em questão; que os membros dessa coletividade realmente se interessem pelos assuntos locais que lhes dizem respeito; e que não se perca o elo com o poder central, que, inclusive, se reserva o direito de manter certo controle, "tutela administrativa", para não haver excesso de independência (FELICÍSSIMO, 1991, p. 66).

Seja como for, deve-se concordar com Gentilini (1999), quando afirma que

[...] a descentralização é uma exigência necessária de um processo mais amplo de modernização das relações entre o Estado e a Sociedade e de necessária reorganização de seu aparato administrativo e político institucional para dar conta de um acelerado processo de mudanças, sociais e econômicas, no qual o próprio Estado não intervém com a mesma eficiência. A sociedade na América Latina teria chegado a uma complexidade sócio-econômica na qual não caberiam mais as tradicionais relações que sempre condicionaram os mecanismos de apropriação e distribuição de recursos, de gestão de políticas públicas e de ampliação e acesso à educação na região, como o clientelismo, o personalismo político ou o corporativismo. (GENTILINI, 1999, p. 43)

A descentralização é muitas vezes confundida com desconcentração, que significa multiplicar a presença do centro, redistribuir em vários locais a ação planejada pelo Estado.

Funções desempenhadas pelo governo federal, por exemplo, podem ser transferidas a órgãos regionais, estaduais e/ou municipais. As unidades subordinadas [...] se tornarão encarregadas de executar as ordens ou implementar os programas a elas repassados pela 'cabeça do sistema'. Assim operarão sob comando e controle dos níveis superiores. (MEDINA, 1987, p.46)

Mas se há uma confusão de entendimento por parte de diferentes governantes, em diferentes momentos históricos, há também alguma confusão teórica:

transferência de responsabilidade pelo planejamento, administração, levantamento e alocação de recursos do governo central e suas agências para: a) as unidades de campo dos ministérios ou agências do governo central; b) as unidades subordinadas ou os níveis de governo; c) as autoridades ou corporações públicas semi-autônomas; d) as autoridades regionais ou funcionais; e) as organizações não governamentais privadas ou voluntárias. (RONDINELLI, 1981 apud SANTOS FILHO, 1990, p. 33)

Pode-se, neste caso, registrar a ausência do "quesito" autonomia política, sem o qual o planejamento pode se reduzir a planejamento da execução de uma política decidida no nível central de governo. 
Casassus (1995) chama a atenção para um complicador na confusão, a lógica que se depreende das dinâmicas do processo que envolve desconcentração e descentralização:

Normalmente, quando se consideram as políticas de descentralização, pode-se observar que, na prática, trata-se de políticas de desconcentração que, eventualmente, podem se transformar em políticas de descentralização. Elas se apresentam como um continuum, no qual em algum momento a desconcentração se transforma em descentralização; no qual há momentos em que se está mais desconcentrado, menos descentralizado e logo se passa a um momento no qual se está mais descentralizado e menos desconcentrado. Essa forma corrente de ver a situação ofusca a natureza dos processos que ocorrem e sugere que, primeiro, é necessário passar por uma fase de desconcentração para, em seguida, passar para uma etapa de descentralização, que viria como consequência lógica. (CASASSUS, 1995, p. 39)

Ultimamente, no Brasil, as formas sob as quais se apresenta a descentralização também são indicadoras de quais mudanças se pretende efetivar. O Governo Federal, no bojo da Reforma de Estado, adota a ideia, divulga e dá início à implementação da descentralização na forma que se dá entre níveis de governo - mais especificamente, a municipalização. Uma outra forma é a que transfere poder do Estado para a sociedade civil. No caso da primeira, o chamado esgotamento do modelo de Estado centralizador e paternalista - que se manifestou na crise fiscal, junto com a crise econômica mundial - levou a uma situação de colapso financeiro e apontou a necessidade da descentralização. Esta, junto a uma série de outras ações, tais como privatização das estatais, diminuição do funcionalismo, reformas no sistema previdenciário, entre outras, cumpririam com a função de desonerar o Estado. No segundo caso - transferência de funções do Estado para a sociedade civil, que compreende tanto empresas privadas quanto organizações civis -, está contida complementarmente a mudança paradigmática no que se refere à concepção de Estado, que passa a ser menor em "tamanho", porém com maior força. Isso se traduziria em maior poder do Estado para fornecer diretrizes, controlar e analisar os resultados, e em diminuição voluntária de responsabilidades no provimento de suas atribuições constitucionais nas áreas sociais, sobretudo na educação. Os que defendem tal forma de descentralização acreditam que a sociedade civil não só tem que cooperar, ou mesmo chamar para si o cuidado com as áreas sociais, como também tem que aportar recursos para essas áreas.

No entanto, quando se busca caracterizar tais formas de descentralização, mais uma vez encontramos na literatura não só formas como também tipologias da descentralização. Santos Filho (1990), ao conceituar descentralização, reporta-se à classificação de Fesler: territorial e funcional. O primeiro tipo seria a descentralização do governo central para os governos estaduais; e o segundo, seguindo a base funcional e hierárquica, descentralizaria poder dos funcionários federais. O referido autor (1990) apresenta ainda a dimensão definida a partir de Pescador, em que a descentralização administrativa se apresenta sob três formas. São elas: por serviços técnicos, por função territorial e por cooperação, tendo como pressuposto que a descentralização administrativa é "uma forma de organização que atribui autonomia orgânica a certos componentes institucionais" (PESCADOR, 1985, apud FELICÍSSIMO, 1991, p. 64). Rondinelli (1986) classificou os tipos de descentralização mais encontrados nos países em desenvolvimento: desconcentração, delegação, devolução e privatização. 
A primeira, que não constitui novidade (e embora não sendo exatamente descentralização), consiste na transferência de autoridade ou responsabilidade administrativa a níveis inferiores do governo federal.

(A delegação) consiste na transferência de responsabilidade administrativa por funções especificamente definidas para organizações situadas fora da estrutura burocrática regular e cujo controle pelo governo central é apenas indireto [...] pode ser feita para empresas públicas, agências de desenvolvimento regional e mesmo organizações paraestatais. (RONDINELLI, 1986 apud FELICÍSSIMO, 1991, p. 65)

A devolução é o tipo de descentralização que implica criar ou fortalecer, financeiramente ou legalmente, unidades subnacionais de governo cujas atividades estejam fora de controle direto do governo central. E, por fim, tem-se a privatização, caso em que o governo transfere algumas de suas atribuições/responsabilidades a organizações voluntárias ou empresas privadas.

Poder-se-ia seguir com exemplos de muitas outras variáveis, mas as citadas nos parecem suficientes para formar uma ideia da multiplicidade de caminhos que podem ser percorridos pela descentralização, de sua concepção à sua implementação. Retomando o caráter internacional do movimento de descentralização do poder público, buscamos inspiração nos estudos de alguns pensadores franceses (LAURENT THÉVENOT e JOËLLE AFICHARD, 1997), por considerar que as razões que os levaram a esse movimento não diferem tanto das razões brasileiras. Assim, Joële Affichard nos aponta, em primeiro lugar, a crítica à administração pública, diagnosticando-a como uma estrutura hierárquica ineficaz por ser centralizada do ponto de vista da gestão. Dessa forma, as instituições públicas representariam um tipo de organização que estimula o funcionamento burocrático, “desresponsabiliza” os agentes, favorece a instalação de rotinas, deixa acontecer o desperdício e conduz, finalmente, à não satisfação das necessidades dos usuários.

Também há que se considerar a inadequação das categorias que informam e orientam as ações do poder público - muito genéricas para resolver / tratar os assuntos em causa. Critica-se o tratamento dado aos usuários dos serviços públicos por seu caráter "impessoal", e a ignorância e falta de autonomia dos funcionários para enfrentar a realidade das situações concretas. Ou seja, prisioneiro das categorias genéricas, o Estado se priva das possibilidades locais, do conhecimento que os atores locais têm do terreno, da dinâmica que poderia se instaurar entre eles; em resumo, das capacidades de coordenação local.

Outra razão que o mesmo autor levanta é a dificuldade crescente do poder público em tratar o problema da compatibilidade das exigências contraditórias. As exigências de valores como justiça, eficácia, inovação e qualidade dos serviços por parte da população são, frequentemente, de difícil conciliação quando postas diante de situações concretas. Por outro lado, o tratamento local dos conflitos supõe uma acomodação desses princípios (AFFICHARD, 1997).

Mas, se há semelhanças nas razões, encontramos diferenças que colocam o caso brasileiro em situação peculiar: a nossa realidade, a nossa história, as nossas tradições culturais. Daí a necessidade de se realizar uma retrospectiva histórica, a partir do surgimento do Estado brasileiro. Mas notemos, desde já, que, como observa Lobo (1990),

[...] a história deste país tem mostrado um nítido predomínio de arranjos político- institucionais centralizadores [...] 
A herança colonial fez deste país um campo fértil aos modelos políticos e econômicos que tinham a centralização de poderes e recursos como seu pressuposto básico. Os resultados não foram dos melhores. (LOBO, 1990, p. 6)

Ao crescimento da capacidade produtiva com o processo de desenvolvimento econômico, desde o fim da República Velha, correspondeu igualmente o crescimento e a consolidação da má distribuição dos benefícios obtidos por esse desenvolvimento, gerando graves desigualdades e carências sociais básicas e profundas, para grande parcela da população brasileira.

No histórico das relações institucionais, o Estado Nacional, ao expandir-se, foi acumulando a função de articulador das relações territoriais e centralizando todas as decisões sobre a organização das políticas públicas. Os questionamentos levantados em relação a essa prática, no bojo da redemocratização mais recente, - somados aos ajustes macroeconômicos implementados pela crise econômica e às limitações da centralização, e com a consciência de que a centralização já não servia ao projeto político - fizeram com que a descentralização ressurgisse como a grande solução. Para o próprio Estado, solução de se desonerar dos gastos destinados às áreas sociais; para os setores democráticos, como uma grande esperança.

Outra razão, aliada às anteriores, diz respeito ao que terá levado as relações intergovernamentais - sempre estabelecidas a partir de uma lógica centralizadora - a um desequilíbrio federativo, no qual prevaleciam "situações de subordinação, política, técnica e financeira de estados e municípios frente ao governo federal” (LOBO, 1990, p.7).

O interessante é que parece haver um relativo consenso quanto à necessidade de descentralizar, mas as razões e os procedimentos variam bastante. O movimento de descentralização desponta como iniciativa do governo federal no sentido de apresentar e implantar o que ele entende que seja uma das soluções para a crise fiscal do Estado. Mas, se observarmos melhor, - mesmo que restritos ao contexto das políticas sociais e, mais especificamente, à questão educacional -, veremos que a descentralização atende também a recomendações de organismos internacionais como o Banco Mundial e o Banco Interamericano de Desenvolvimento, no sentido de responder à crise dos sistemas de ensino de vários países.

É preciso, portanto, que se tenha clareza sobre o fato de que processos de descentralização, desconcentração e democratização são distintos, embora muitas vezes considerados sinônimos. Descentralização tem uma dimensão política e implica a redistribuição de poder e o deslocamento dos processos decisórios; desconcentração tem uma dimensão administrativa e implica a delegação de competências e responsabilidades sem deslocamento do processo decisório (ABREU, 1998).

Descentralização não implica necessariamente democratização, assim como centralização não pode ser necessariamente associada a práticas autoritárias. A descentralização pode surgir como forma de reforçar o aparelho de dominação, ou de contribuir para a construção de processos democráticos quando houver participação popular nos processos decisórios - seja por meio de processos eleitorais, seja através de conselhos - e quando houver controle social, por intermédio do acesso às informações, da transparência dos processos de gestão e de decisão (ABREU, 1998; TOBAR, 1991). Por democrático,

entende-se primariamente um conjunto de regras de procedimento para a formação de decisões coletivas, em que está previs- 
ta e facilitada a participação mais ampla possível dos interessados. (BOBBIO, 1986. p. 12)

A participação popular é aqui considerada um princípio democrático - e não aquele receituário político, que costuma ser aplicado como medida ou propaganda de um governo sem continuidade institucional [...]. É a realização concreta da soberania popular, mais importante do que a atividade eleitoral que se esgota na escolha para cargos executivos ou legislativos [...] Essa participação supõe possibilidade de criação, transformação e controle sobre o poder ou os poderes. (BENEVIDES, 1995, p.119)

Embora o movimento de descentralização esteja apontando para o fortalecimento da capacidade decisória das instâncias subnacionais - estados e municípios -, não é visível que tal processo esteja sendo acompanhado da democratização das relações entre Estado e sociedade e entre os diferentes segmentos dessa sociedade.

A descentralização será democrática quando assegurar à população possibilidades de participação no processo decisório, com representação pluralista de setores sociais organizados, quando houver compromisso com a transparência das discussões e encaminhamentos, e garantia da divulgação e veiculação das informações. A descentralização será não democrática quando restringir apenas à minoria os processos decisórios.

\section{Refências}

ABREU, M. Organização da educação nacional na legislação vigente. Porto Alegre: Unijuí, 1998.
AFFICHARD, J. Décentralisation desorganisations et problème de

coordination: les principaux cadres d'analyse. Paris: Éditions L'Harmattan, 1997.

BENEVIDES, M. V. Participação popular na nova constituição: um corretivo à representação política. Brasil em Artigos. São Paulo: SEADE, 1995.

BOBBIO, N. O futuro da democracia: uma defesa das regras do jogo. Rio de Janeiro: Paz e Terra, 1986.

BOISIER, S.Losprocessosdedescentralización y desarrollo regionalen el scenário actual de América Latina. Revista da CEPAL. Santiago do Chile, n.31, ago., 1987.

BORJA, J. (Org.). Descentralizacón del estado, movimineto social y gestión local. Santiago do Chile: Editorial FLACSO, 1987.

CASASSUS, Juan. A centralização e a descentralização da educação. Cadernos de Pesquisa. São Paulo, n.95, p.37-42, nov., 1995.

FELICÍSSIMO, J. R. Descentralização e regionalização políticoadministrativa. Revista São Paulo em Perspectiva, Fundação Seade, v.5, n.4, out./dez., p.60-72, 1991.

GENTILINI, J. A. Crise e planejamento educacional na América Latina: tendências e perspectivas no contexto da descentralização. Campinas, 1999. Tese (Doutorado em Educação). Faculdade de Educação da Universidade Estadual de Campinas

LOBO, T. Descentralização: conceitos, princípios, prática governamental. Cadernos de Pesquisa, Campinas, n.74, p.5-10, agosto, 1990.

MEDINA, A. V. A. Tarefas ou poder: o que descentralizar? Cadernos de Pesquisa, Campinas, n.60, p.45-47, fevereiro, 1987. 
RONDINELLI, D. Governement descentralization in comparative perspective theory and practice in developing countries. Internation Review of Administrative Science, v.47, n.2, p.133-145, 1981.

RONDINELLI, D. et al. Decentralization in developing countries: a review of recent experience. Washington: The Word Bank, 1986.

SANTOS FILHO, J. C. Federalismo, poder local e descentralização. Educação Municipal. São Paulo, v.3, n.6, p.20-36, junho, 1990.

THÉVENOT, L. Tensions critiques et compromis entre définitions du bien commun: l'approche des organisations par la théorie de la justification. In: AFFICHARD, J. Décentralisation des organisations et problèmes decoordination: les principaux cadres d'analyse. Paris: Editions L'Harmattan, 1997.

TOBAR, F. O conceito de descentralização: usos e abusos. Revista Planejamento e Políticas Públicas. n.5, junho, p.31-51, 1991.

Enviado em: 12/12/2011

Aceito em: 18/12/2011 